\title{
A comparison of electrical and photonic pulse generation for IR-UWB on fiber links
}

Rodes Lopez, Roberto; Caballero Jambrina, Antonio; Yu, Xianbin; Gibbon, Timothy Braidwood; Jensen, Jesper Bevensee; Tafur Monroy, Idelfonso

Published in:

I E E E Photonics Technology Letters

Link to article, DOI:

10.1109/LPT.2009.2037826

Publication date:

2010

Document Version

Publisher's PDF, also known as Version of record

Link back to DTU Orbit

Citation (APA):

Rodes Lopez, R., Caballero Jambrina, A., Yu, X., Gibbon, T. B., Jensen, J. B., \& Tafur Monroy, I. (2010). A comparison of electrical and photonic pulse generation for IR-UWB on fiber links. I E E E Photonics Technology Letters, 22(5), 263-265. https://doi.org/10.1109/LPT.2009.2037826

\section{General rights}

Copyright and moral rights for the publications made accessible in the public portal are retained by the authors and/or other copyright owners and it is a condition of accessing publications that users recognise and abide by the legal requirements associated with these rights.

- Users may download and print one copy of any publication from the public portal for the purpose of private study or research.

- You may not further distribute the material or use it for any profit-making activity or commercial gain

- You may freely distribute the URL identifying the publication in the public portal 


\title{
A Comparison of Electrical and Photonic Pulse Generation for IR-UWB on Fiber Links
}

\author{
Roberto Rodes Lopez, Antonio Caballero, Xianbin Yu, Timothy Braidwood Gibbon, Jesper Bevensee Jensen, and \\ I. Tafur Monroy, Member, IEEE
}

\begin{abstract}
We present and compare experimental results for electrical and photonic generation of $2-\mathrm{Gb} / \mathrm{s}$ pulses for impulse radio ultra-wideband on fiber transmission systems based on direct current modulation of a semiconductor laser diode and external optical injection of a semiconductor laser diode, respectively. We assess the performance of the two generation approaches in terms of bit-error rate after propagation over $20 \mathbf{~ k m}$ of optical fiber followed by wireless transmission.
\end{abstract}

Index Terms-Impulse radio ultra-wideband (IR-UWB), personal area networks, radio-over-fiber, short range wireless link.

\section{INTRODUCTION}

I MPULSE radio ultra-wideband (IR-UWB) communication is gaining much attention as a promising technique for highcapacity short-range wireless links with low emission power levels. Applications that can benefit from such systems include wireless distribution of high-definition TV signals at indoor networking scenarios [1]. However, due to the short coverage range of IR-UWB systems, signal distribution over an optical fiber network are of interest as well as this trend offers capabilities for integration of wireless and wireline signal distribution into a common optical fiber infrastructure to the customer premises [2]. As the demand for capacity is requiring bit rates above $1 \mathrm{~Gb} / \mathrm{s}$, the generation of high-speed impulse signals, complying with the stipulated ultra-wideband (UWB) emission frequency mask is a challenging task. Moreover, the performance evaluation and comparison of generated waveforms by different techniques and their transmission performance over optical fiber is relevant to support the development of IR-UWB over optical fiber links. In this letter, we compare and assess the performance of two approaches for pulse generation, complying with the Federal Communications Commission (FCC) regulated emission mask [3] at $2 \mathrm{~Gb} / \mathrm{s}$, namely an electronic approach, using a high-speed arbitrary waveform generator (AWG), and a photonic approach employing optical injection of a semiconductor laser diode. Bit-error-rate measurements are presented for an IR-UWB link over 20-km optical fiber link with subsequent wireless transmission over 6- and 8-m distances.

Manuscript received August 27, 2009; revised November 18, 2009; accepted November 19, 2009. First published January 12, 2010; current version published February 03, 2010. This work was supported in part by the European Community's Seventh Framework Programme (FP7/2007-2013) project ICT-ALPHA.

The authors are with DTU Fotonik, Department of Photonics Engineering, Technical University of Denmark, 2800 Kgs. Lyngby, Denmark (e-mail: idtm@fotonik.dtu.dk).

Color versions of one or more of the figures in this letter are available online at http://ieeexplore.ieee.org.

Digital Object Identifier 10.1109/LPT.2009.2037826

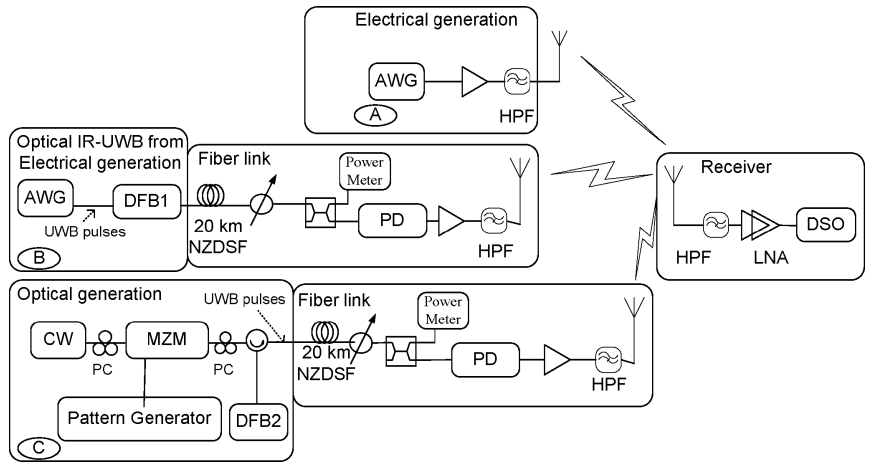

Fig. 1. Experimental setup. MZM: Mach-Zehnder modulator; DSO: digital sampling scope; $\mathrm{CW}$ : continuous-wave laser source.

\section{IMPULSE GENERATION APPROACHES}

\section{A. Electrical Generation}

The electrical generation is done by an AWG with 9-GHz bandwidth and a sample rate of $24 \mathrm{GSa} / \mathrm{s}$. ON-OFF keying with a pseudorandom bit sequence (PRBS) of word length $2^{11}-1$ is used. The pulse shape is a fifth-order derivative Gaussian pulse, which is known to agree well with the spectrum requirements for UWB systems [4].

\section{B. Photonic Generation}

The photonic generation setup is shown in Fig. 1 and it is based on the previously reported method in [5]. A conventional pulse pattern generator is set at $10-\mathrm{Gb} / \mathrm{s}$ bit rate and used to drive an optical intensity Mach-Zehnder modulator (MZM). Five bit patterns " 10000 " and "00000" are used to represent a binary one and zero, respectively, resulting in 2-Gb/s effective IR-UWB bit rate. An optical circulator (OC) is utilized to separate the lightwave launched into the distributed-feedback (DFB) laser from its output lightwave. Cross-gain modulation inside the DFB in combination with relaxation oscillations results in an optical pulse whose shape is close to a fifth-order derivative Gaussian pulse.

\section{EXPERIMENTAL SETUP}

The schematic diagrams of our experimental setups used for our assessment are depicted in Fig. 1. Setup A is employed for wireless transmission only. The IR-UWB signal from the AWG with $0.5-\mathrm{V}$ peak-to-peak value is amplified by $8 \mathrm{~dB}$ by a broadband amplifier. A high-pass filter (HPF), with a cut-off frequency of $3.1 \mathrm{GHz}$, is placed before the transmitter antenna to ensure that the signal fits inside the spectrum available for UWB technology. The transmitter antenna was an omni-directional antenna with 4.4-dBi gain at peak frequency of $4.5 \mathrm{GHz}$, 
while the receiver antenna was a bowtie phased-array with a gain which varies from 4.65 to $12.5 \mathrm{dBi}$ within the 3.1 - to $10.6-\mathrm{GHz}$ UWB spectrum, and has a value of $8.8 \mathrm{dBi}$ at the signal peak frequency of $5 \mathrm{GHz}$. From a practical point of view, this configuration is advantageous as it only requires alignment of the receiving antenna, whereas the transmitting antenna can be fixed disregarding the in-room placement of the receiver. At the receiver site, the received signal is high-pass filtered and amplified by a two-stage low noise amplifier (LNA). The total amplifier gain was $49 \mathrm{~dB}$. A digital sampling oscilloscope (DSO), with a $40-\mathrm{GSa} / \mathrm{s}$ rate over $13-\mathrm{GHz}$ bandwidth, digitizes and stores the received signal. Setup B is used to assess the performance of IR-UWB over fiber transmission. The electrically generated IR-UWB signal directly modulates a DFB at a wavelength of $1550 \mathrm{~nm}$. The driving peak-to-peak voltage was $270 \mathrm{mV}$, and the bias current was $27 \mathrm{~mA}$. Setup $\mathrm{C}$ is used to assess the performance of the photonically generated pulse. The optical fiber link is composed of $20 \mathrm{~km}$ of nonzero dispersion-shifted fiber (NZDSF) and a photodiode (PD). Total fiber loss and dispersion were $5.4 \mathrm{~dB}$ and $108 \mathrm{ps} / \mathrm{nm}$, respectively. The input power to the PD was $-7 \mathrm{dBm}$. NZDSF was chosen in order to focus on the generation methods and the imposition process of the IR-UWB into the optical carrier rather than the effect of chromatic dispersion issues; which are left for further study. The output signal from the PD was amplified $24 \mathrm{~dB}$ by a broadband amplifier. All three setups employ the same antenna configuration, HPF filter before and after transmission, amplification at the receiver and digital signal processing (DSP) receiver algorithm. Data demodulation was performed using an off-line algorithm which performs synchronization, calculates the correlation between the received signal and a fifth-order derivative Gaussian pulse before performing single-threshold decision gating.

\section{RESULTS}

\section{A. IR-UWB Pulse Patterns}

Fig. 2 shows an example of the IR-UWB pulse pattern electrically generated at different points in the experimental setup. In Fig. 2(b), we can observe oscillations at the zero level at the output of the AWG, compared to the Matlab pulse design, due to the AWG bandwidth and bit resolution limitation. Fig. 2(c) shows the measured pulse pattern after electrical-to-optical conversion, where we can observe the signal degradation introduced during direct current DFB modulation. Inverse biasing operation of the DFB results also in pulse inversion. In Fig. 2(d), the pulse pattern after $20 \mathrm{~km}$ of fiber transmission is shown, with no major observable degradation compared to its DFB output version. An example of the IR-UWB pulse pattern generated by the photonic scheme is presented in Fig. 3(a) and (b), back-to-back and after fiber transmission, respectively.

By setting the DFB bias current level to $-22.67 \mathrm{~mA}$ and input optical average power to $-6.15 \mathrm{dBm}$, the resultant pulse shape is close to a fifth-order derivative Gaussian pulse shape. Similar to the electrical generation case, after $20 \mathrm{~km}$ of fiber transmission, no significant pulse degradation is observed compared to its back-to-back case.

\section{B. FCC Mask Compliance}

We have assessed the compliance with the FCC mask regulation for both schemes, after fiber transmission, before wireless transmission. To take into account the frequency response of the
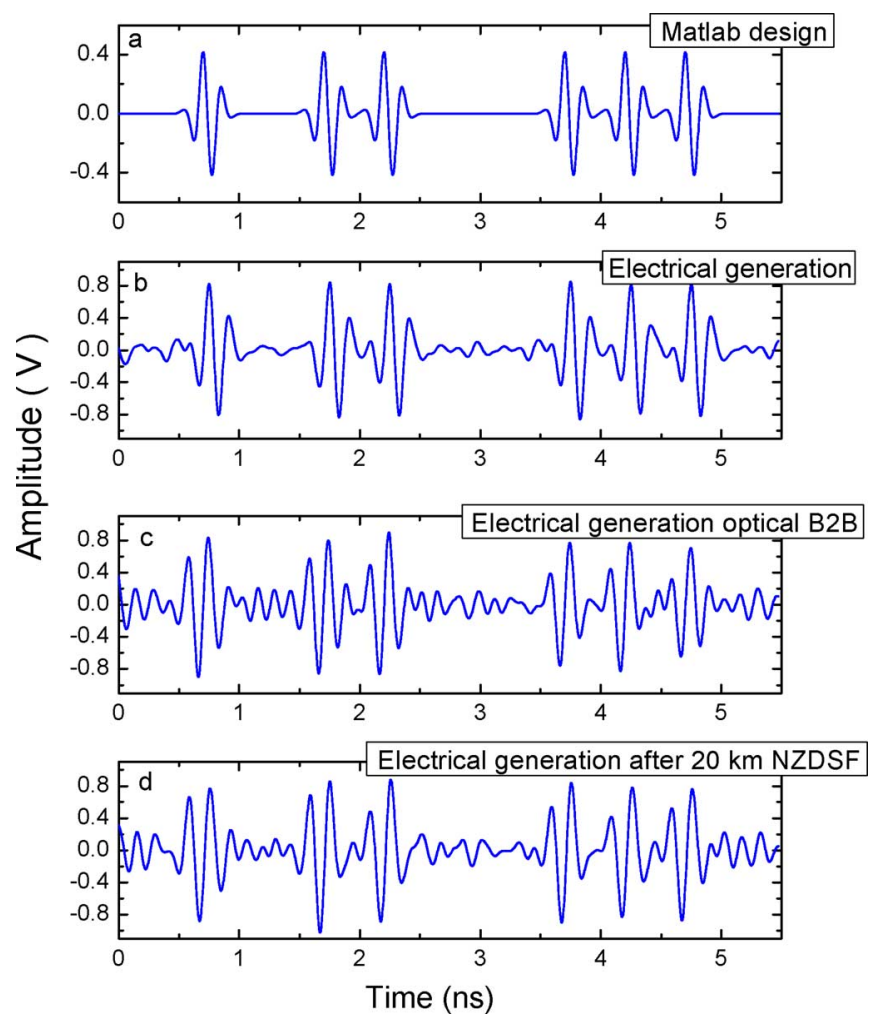

Fig. 2. Electrical generation method. Example of measured IR-UWB signal pattern along the system.

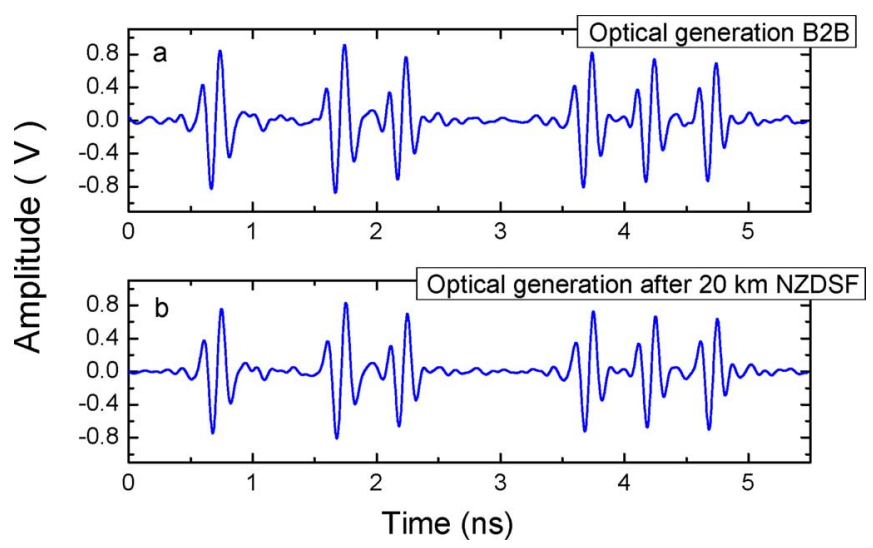

Fig. 3. Photonic generation method. (a) Back-to-back and (b) after $20 \mathrm{~km}$ of fiber transmission.

transmitter antenna, the effective allowed mask in our experimental setup is characterized as explained in [6], and the result is shown in Fig. 4. We can observe that both schemes satisfy the effective allowed mask. The visible spikes in both masks at multiples of the pulse repetition frequency are below $20 \mathrm{~dB}$, which are allowed to rise above the mask as specified by the regulations [3], [4].

\section{Wireless Transmission}

To continue our performance assessment and comparison, we have analyzed the wireless transmission performance. We have computed the eye diagram, after DSP processing of the measured data as well as the number of errors, from $10^{5}$ measured bits. This corresponds to more than 48 replicas of the UWB 


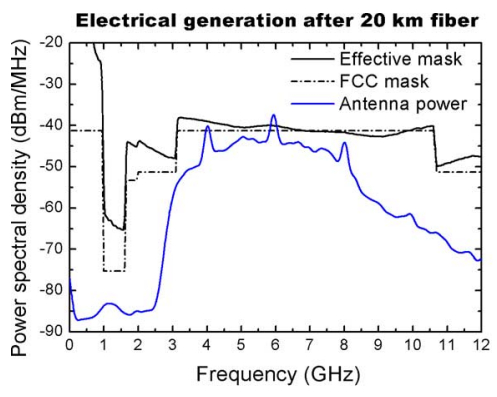

(a)

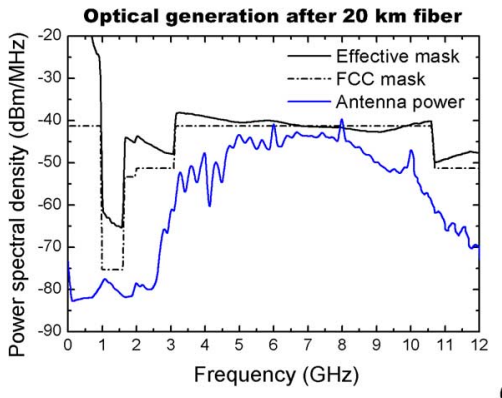

(b)

Fig. 4. Effective allowed emission mask, according to FCC regulation, for both our electrically and photonically generated IR-UWB signals.
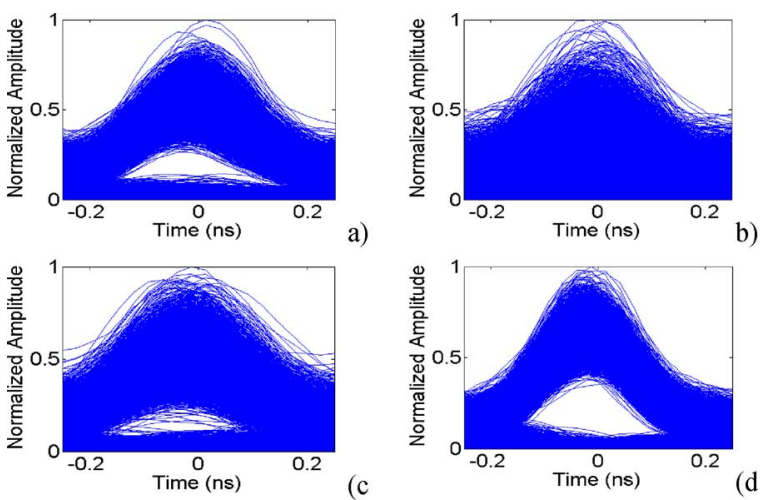

Fig. 5. (a) Electrical generation with 8-m wireless transmission only (setup A), bit-error rate (BER) $<10^{-5}$. (b) Electrical generation with fiber and 8-m wireless transmission (setup $\mathrm{B}$ ), BER $=3 \times 10^{-2}$. (c) Electrical generation with fiber and 6-m wireless transmission ( $\left(\right.$ etup B), BER $=6 \times 10^{-5}$. (d) Photonic generation with fiber and 8-m wireless transmission (setup C), BER $<10^{-5}$.

PRBS of length $2^{11}-1$, limited by the pattern length programmability of the pattern generator used for optical generation.Fig. 5(a) shows the eye diagram of the electrically generated case, with only wireless transmission over $8 \mathrm{~m}$. As we can see in Fig. 5(a), the eye diagram is wide open and no error was detected in $10^{5}$ bits, resulting in a distance-bit rate product of $16 \mathrm{~Gb} / \mathrm{s} \cdot \mathrm{m}$. Fig. 5(b) shows the received signal eye diagram for the electrically generated signal after $20 \mathrm{~km}$ of fiber propagation and $8-\mathrm{m}$ wireless transmission, where we can observe a closed eye diagram. Fig. 5(c) shows an open eye diagram for the same setup. In this case, we decreased the distance until $6 \mathrm{~m}$ to achieve error-free detection. Therefore, the resulting distance-bit rate product for setup B is $12 \mathrm{~Gb} / \mathrm{s} \cdot \mathrm{m}$. Fig. 5(d) presents the received eye diagram for the photonically generated case, showing an open eye for 8-m wireless transmission. No error was detected in $10^{5}$ bits, resulting in a distance bit rate product of $16 \mathrm{~Gb} / \mathrm{s} \cdot \mathrm{m}$. It is expected that a Rake receiver, which combines different signal components from different paths, can increase the signal-to-noise ratio and improve further the link performance [7].

As we can observe from Fig. 4(a) and (b), the photonically generated pulses show highest frequency components and a more symmetric spectrum around the central UWB frequencies than the electrically generated pulses. This is due mainly to the bandwidth limitation of the AWG to $9 \mathrm{GHz}$. Moreover, direct current modulation of the DFB introduces signal degradation (see Fig. 2) due to the nonlinear modulation characteristics of the DFB and its accompanying frequency chirp. We associate the worse performance of the electrically generated pulses with the two above effects. Therefore, a further study on shaping the generated pulses in the AWG to reduce chirp from the direct modulation DFB laser is identified.

\section{CONCLUSION}

We have experimentally assessed the performance of two IR-UWB methods after propagation over $20 \mathrm{~km}$ of optical fiber followed by wireless transmission. Our measurements showed a better performance in terms of bit-rate wireless distance, after fiber propagation, for the photonic pulse generation methods, attributed mainly to its lower bandwidth limitation compared to the electrical method. The electrical generation approach allows for employing direct current modulation of laser sources, potentially offering a less complex system than the current photonic generation method; however, it requires an IR-UWB pulse generator that is a no low cost solution at present. Both electrical and photonic generation methods would benefit from advances in reducing generation complexity, versatile pulse shaping, and integration with optical fiber links for applications in high-speed wireless short-range communication systems.

\section{REFERENCES}

[1] B. Allen, T. Brown, K. Schwieger, E. Zimmermann, W. Q. Malik, D. J. Edwards, L. Ouvry, and I. Oppermann, "Ultra-wideband: Applications, technology and future perspectives," in Proc. Int. Workshop Convergent Tech., Oulu, Finland, Jun. 2005.

[2] R. Llorente, T. Alves, M. Morant, M. Beltran, J. Perez, A. Cartaxo, and J. Marti, "Ultra-wideband radio signals distribution in FTTH networks," IEEE Photon. Technol. Lett., vol. 20, no. 11, pp. 945-947, Jun. 1,2008

[3] Revision of Part 15 of the Commission's Rules Regarding Ultra-Wideband Transmission Systems Federal Communications Commission, Feb. 2002.

[4] H. Sheng, P. Orlik, A. M. Haimovich, L. J. Cimini Jr., and J. Zhang, "On the spectral and power requirements for ultra wideband transmission," in Proc. IEEE Int. Conf. Communications, 2003, pp. 738-742.

[5] X. Yu, T. B. Gibbon, M. Pawlik, S. Blaaberg, and I. T. Monroy, "A photonic ultra-wideband pulse generator based on relaxation oscillations of a semiconductor laser," Opt. Express, vol. 17, no. 12, pp. 9680-9687, 2009.

[6] M. Abtahi, M. Mirshafiei, J. Magn, S. LaRochelle, and L. A. Rusch, "All-optical 500-Mb/s UWB transceiver: An experimental demonstration," J. Lightw. Technol., vol. 26, no. 15, pp. 2795-2802, Aug. 1, 2008.

[7] I. Oppermann, M. Hämäläinen, and J. Linatti, UWB Theory and Applications. Chichester, U.K.: Wiley, 2004 